\title{
THE
}

\section{Using Acoustic Travel Time to Determine Dynamic Height Variations in the North Atlantic Ocean}

\author{
Geoffrey Trivers \\ University of Rhode Island \\ Mark Wimbush \\ University of Rhode Island, mwimbush@uri.edu
}

Follow this and additional works at: https://digitalcommons.uri.edu/gsofacpubs

\begin{abstract}
Citation/Publisher Attribution
Trivers, G., \& Wimbush, M. (1994). Using Acoustic Travel Time to Determine Dynamic Height Variations in the North Atlantic Ocean. Journal of Atmospheric and Oceanic Technology, 11, 1309-1316. doi: 10.1175/ 1520-0426(1994)0112.0.CO;2 Available at: http://doi.org/10.1175/1520-0426(1994)0112.0.c0;2
\end{abstract}

This Article is brought to you for free and open access by the Graduate School of Oceanography at DigitalCommons@URI. It has been accepted for inclusion in Graduate School of Oceanography Faculty Publications by an authorized administrator of DigitalCommons@URI. For more information, please contact digitalcommons-group@uri.edu. 


\title{
Using Acoustic Travel Time to Determine Dynamic H耳ight Variations in the North Atlantic Ocear
}

\author{
GEOFFREY TRIVERS* AND MARK WIMBUSH \\ Graduate School of Oceanography, University of Rhode Island, Narragansett, Rhode Island
}

(Manuscript received 1 January 1993, in final form 22 February 1994)

\begin{abstract}
There is often an approximately linear relationship between various water-column integrals, in particular between surface dynamic height anomaly $\Delta D$ and acoustic round-trip travel time $\tau$. Consequently, the record from an inverted echo sounder, which measures $\tau$, can be interpreted in terms of $\Delta D$. Nevertheless, the slope $m$ of this linear relation is not everywhere well defined, and varies from place to place. This study seeks to establish where, in the extratropical North Atlantic, one can reasonably assume a linear relation between $\Delta D$ and $\tau$, and for these regions compute $m$. Using climatological atlas data and historic hydrographic data, it is shown that a well-defined, linear relation exists between $\Delta D$ and $\tau$ in a region centered on the Gulf Stream and extending from the northern Sargasso Sea almost to Ireland. Where $m$ is well defined, it is negative, and its value is usually similar to that associated with first-baroclinic-mode excitation. Its magnitude generally decreases with increasing latitude. The value of $m$ typically ranges from -40 dyn $\mathrm{m} \mathrm{s}^{-1}$ in the northern Sargasso Sea to -20 dyn $\mathrm{m} \mathrm{s}^{-1}$ in the North Atlantic Current. In the Gulf Stream it is typically between -30 and -35 dyn $\mathrm{m} \mathrm{s}^{-1}$.
\end{abstract}

\section{Introduction}

The inverted echo sounder (IES) is a bottom-moored instrument that measures and records the round-trip travel time $\tau$ of an acoustic pulse, from the seafloor to the sea surface. It was first proposed by Rossby (1969) as a means of monitoring depth variations of the main thermocline, and thus variations in the position of the Gulf Stream. Later, Watts and Rossby (1977) showed how $\tau$ variations measured beneath the Gulf Stream can also be interpreted, through linear relations, as variations in dynamic height anomaly $\Delta D$ and heat content $Q$. Such interpretations for $\Delta D$ have been carried out by several investigators in various regions of the Atlantic (Katz 1987; Hallock 1987) and the Pacific (Miller et al. 1985; Maul et al. 1988; Chiswell et al. 1986, 1987; Chiswell et al. 1988; Wimbush et al. 1990). In these studies, the slope of the linear relationship is invariably negative, but its magnitude varies from one region to another.

Determining the slope of the linear relation between $\tau$ and $\Delta D$ requires supporting information about the sound speed and density profiles in the area where the IES is to be deployed. This determination can be ac-

\footnotetext{
* Current affiliation: U.S. Coast Guard International Ice Patrol, Groton, Connecticut.
}

Corresponding author address: Geoffrey Trivers, U.S. Coast Guard International Ice Patrol, 1082 Shennecossett Road, Groton, CT 06340-6095. complished by taking repeated hydrographic casts during the IES deployment or (more commonly) by using historic profiles from the region of interest. The goal of this study is to extend the latter method by using profiles from a climatological atlas, in addition to historical data, to determine where one can reliably assume

$$
\Delta D^{\prime}=m \tau^{\prime}
$$

(using a prime to indicate fluctuation about the mean), and for these regions compute the value of $m$. A similar study of the correlation of $\tau$ with $Q$ in the North Atlantic is described in Trivers (1992). No actual IES data are used in the work described here. This investigation is limited to the North Atlantic region between the parallels $20^{\circ}$ and $70^{\circ} \mathrm{N}$, and the meridians $10^{\circ}$ and $80^{\circ} \mathrm{W}$ (Fig. 1).

As noted before, Rossby (1969) first proposed and tested the IES as an instrument to monitor changes in the depth of the main thermocline. Using historic data, he found that the linear slope between computed $\tau$ and the depth of the $10^{\circ} \mathrm{C}$ and $12^{\circ} \mathrm{C}$ isotherms was -22.2 and $-20.9 \mathrm{~m} \mathrm{~ms}^{-1}$, respectively. From MODE (MidOcean Dynamics Experiment) data, Watts and Rossby (1977) calculated $m$ in the western Sargasso Sea; their results are summarized in Table 1. Hallock (1987) investigated the variation of $m$ in several regions: southeastern Norwegian Sea, eastern Gulf Stream, and western Sargasso Sea. His results are summarized in Table 2. 


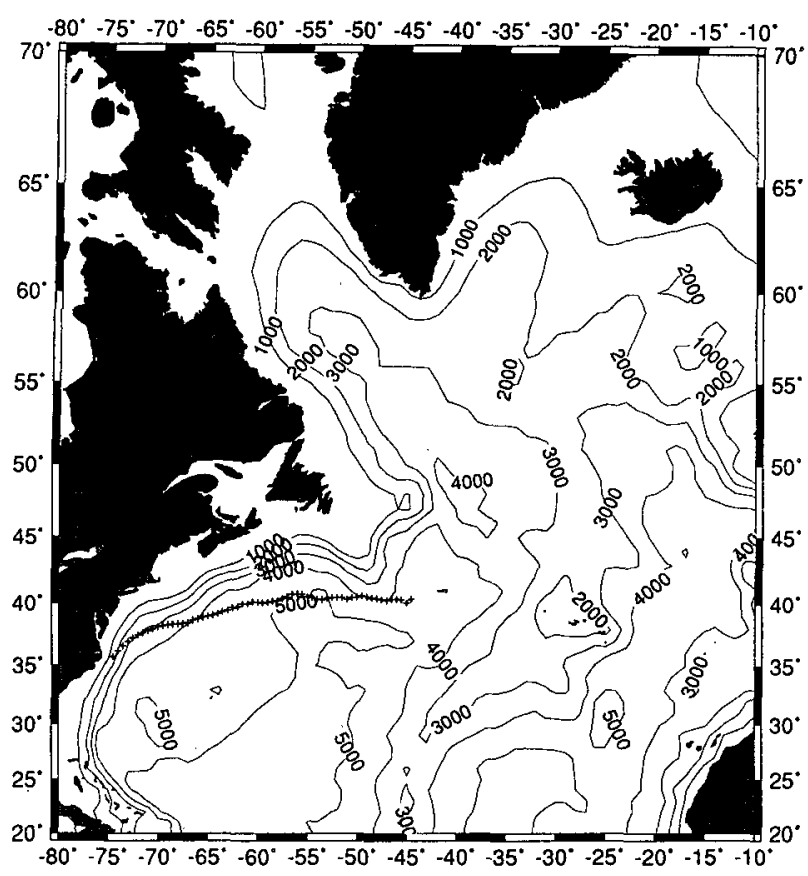

FIG. 1. Area of study showing bottom depth in meters (cross indicates 8-yr mean position, 1982-89, of the Gulf Stream north wall digitized from satellite infrared images; from personal communication with Dr. Tong Lee, University of Rhode Island).

\section{Method}

From profiles of temperature $T$ and salinity $S$, profiles of density $\rho$ and sound velocity $c$ were computed using the equations given in Millero et al. (1980) and Chen and Millero (1977), respectively. Dynamic height anomaly $\Delta D$, and sound round-trip travel time $\tau$ were then calculated using the following relations:

$$
\begin{aligned}
\alpha_{S, T, p} & =\frac{1}{\rho(S, T, p)} \\
\delta & =\alpha_{S, T, p}-\alpha_{35,0, p} \\
\Delta D_{0, p} & =10^{3} \int_{0}^{p} \delta d p \\
\tau_{0, p} & =2 \times 10^{4} \int_{0}^{p} \frac{d p}{\rho g c} .
\end{aligned}
$$

These relations employ SI units throughout, except $\Delta D$ is in dynamic meters and pressure $p$ is in decibars. Gravity $g$ is a function of latitude $\phi$ and pressure $p$, given in Fofonoff and Millard (1983).

Linear regression of $\Delta D_{0, p}$ with $\tau_{0, p}$ then gave slope $m_{l}$ (subscript $l$ for linear) and intercept $a$ for several values of bottom pressure $p(500,1000,2000,3000$, and $4000 \mathrm{db}$ ). For each $p$, least-squares best-fit line $\Delta D_{l}$, error estimate $E_{\Delta D}$, signal-to-noise ratio $\mathrm{SNR}$, and uncertainty in linear slope $\sigma_{m l}$ were computed as follows:

$$
\begin{aligned}
\Delta D_{l} & =m_{l}+a \\
E_{\Delta D} & =\operatorname{rms}\left(\Delta D-\Delta D_{l}\right) \\
\mathrm{SNR} & =10 \log _{10}\left[\frac{\operatorname{rms}\left(\Delta D^{\prime}\right)}{E_{\Delta D}}\right] \\
\sigma_{m_{l}} & =\frac{E_{\Delta D}}{N^{1 / 2} \mathrm{rms}\left(\tau^{\prime}\right)},
\end{aligned}
$$

where $N$ is the number of data points used in the fitting, and $E_{\Delta D}$ is an unbiased error estimate. In addition, we calculated the correlation coefficient $r_{m}$ of $\Delta D$ with $\tau$. The parameters SNR and $r_{m}$ are useful in determining whether or not a specific area is suitable for IES determination of $\Delta \dot{D}^{\prime}$.

Hydrographic profiles from a region (e.g., a $5^{\circ}$ square) are used in determining $m_{l}$ in this way. The implicit assumption here is that temporal variations at a fixed point in the region are mimicked by spatial variations. One way to check this assumption is to compare the $m_{l}$ values computed from a $5^{\circ}$ square with those computed from hydrographic profiles taken at different times within a smaller region (e.g., a $1^{\circ}$ square). By this method, Trivers (1992) showed that, in areas of strong $\Delta D-\tau$ correlation, the characteristics of $\Delta D$ and $\tau$ temporal variations are well represented by their spatial variations.

This spatiotemporal correspondence problem can be bypassed by assuming dynamic height and acoustic travel time changes are due to the first baroclinic mode (Watts and Rossby 1977) or to disturbances resembling this mode. This is accomplished by computing the vertical displacement profile of the first baroclinic mode at each location then, using a small amplitude of this mode, exciting the temperature and salinity fields to compute $\Delta D^{\prime}$ and $\tau^{\prime}$ and, hence, a first-baroclinic " $m_{1}$." Since $\Delta D$ and $\tau$ are both water-column integrals, it is reasonable to expect that they will be predominantly affected by first-mode disturbances, and in any case the first mode is generally more energetic than higherorder modes.

\section{Data sources and analysis}

Two sources of data were used in this study. The first is the Climatological Atlas of the World Ocean (CAWO), summarized by Levitus (1982). The CAWO consists of annual and seasonal averaged datasets on a $1^{\circ}$ latitude-longitude grid for the World Ocean. In this study, we have used only the so-called annual av-

TABLE 1. Watts and Rossby (1977) results.

\begin{tabular}{cccc}
\hline \hline Location & Range & $\begin{array}{c}m \\
\left(\mathrm{dyn} \mathrm{m} \mathrm{s}^{-1}\right)\end{array}$ & $\begin{array}{c}E_{\Delta D} \\
(\mathrm{dyn} \mathrm{m})\end{array}$ \\
\hline Sargasso Sea & $\begin{array}{l}\Delta D 500-1500 \mathrm{db} \\
\tau 0-5400 \mathrm{~m}\end{array}$ & -23.0 & 0.005 \\
\hline
\end{tabular}


eraged dataset, which is henceforth referred to as the CAWO set. The second source of data is a historic set of 2322 casts taken from 1954 to 1964 . The quality of this dataset has been checked by Dr. M. McCartney. It is referred to as the "historic" set. The spatial distribution of casis is shown in Fig. 2.

Since there is spatiotemporal variation in the historic set, whereas the CAWO set has spatial variation only, we do not expect a priori that $m_{l}$ values from the two datasets will be the same.

The CAWO profiles are functions of depth. Depth $(-z)$ was converted to pressure, by iterating the hydrostatic pressure equation:

$$
p(z)=10^{-4} \int_{z}^{0} g \rho(S, T, p) d z,
$$

using $g=9.8 \mathrm{~m} \mathrm{~s}^{-2}$ and numerically setting $p(\mathrm{db})$ $=-z(\mathrm{~m})$ on the right-hand side for the first iteration. The reason for using a fixed $g$ here is that the data on which the CAWO profiles were based had been previously converted from pressure to depth using a fixed $g$. If Fofonoff and Millard's (1983) $g(\phi, p)$ is used instead, the computed pressure drop across the Gulf Stream at a fixed depth of $3000 \mathrm{~m}$ is three times larger than the expected $1 \mathrm{db}$. See Trivers (1992, appendix $D$ ) for further discussion of the effect of $g$ representation on computed pressure and $m_{l}$.

For the purpose of computing $m_{l}$, all stations were binned into $5^{\circ}$ World Meteorology Organization (WMO) squares (Fig. 3). For a given deep-pressure limit $p$, only those squares were used that contained at leasî five profiles extending through pressure $p$. We chose $p=3000 \mathrm{db}$ as the principal deep-pressure limit for the integrals used in the analysis. This square size and pressure level were chosen to give a suitable number of stations, in a square as small as possible, at a pressure as close as possible to a typical bottom pressure. A pressure of $4000 \mathrm{db}$ is closer to the average bottom pressure of the Atlantic ( $3990 \mathrm{db})$, but significantly fewer siations extend to pressures as high as $4000 \mathrm{db}$, especially in the historic dataset. Ten-degree squares would obviously increase the number of stations within a square, but each square would cover such a large area that (judging from Fig. 6) it might be unwise to assume $m$ constant within a square.

Despite the fact that the first-baroclinic-mode method returns an $m_{1}$ at each location, we principally looked at the $m_{1}$ mean and standard deviation $\left(\sigma_{m_{1}}\right)$ within each $\mathrm{WM} / \mathrm{O} 5^{\circ}$ square. In each $5^{\circ}$ bin, only those

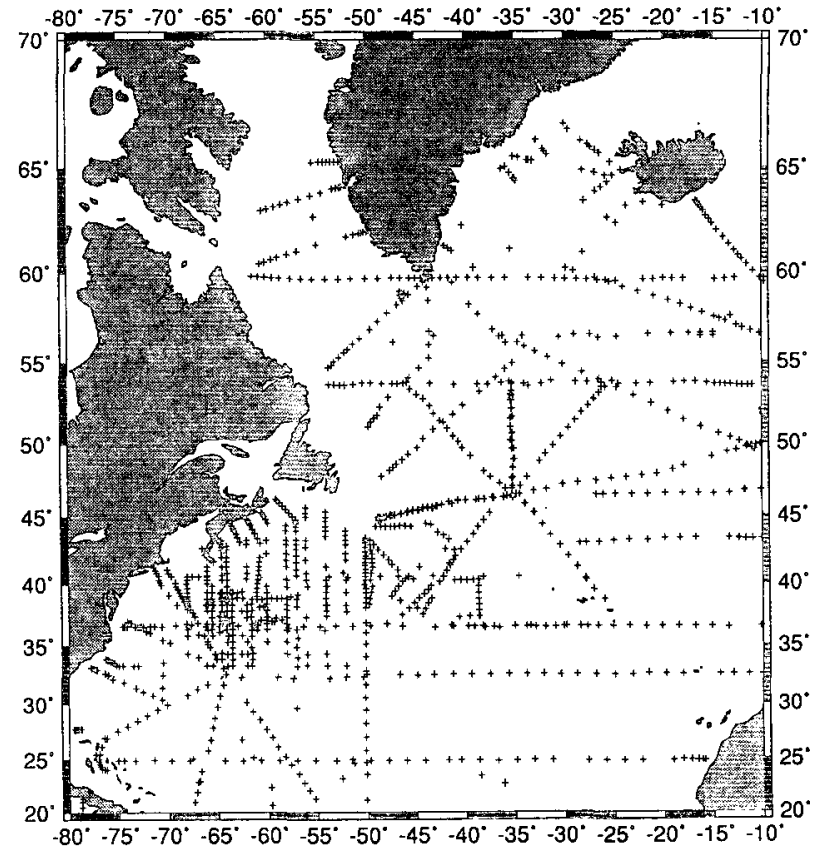

FIG. 2. Historic dataset cast locations.

profiles (CAWO or historic) that extend beyond the pressure limit $p$ and that have $m_{1}$ values between 0 and -150 dyn $\mathrm{m} \mathrm{s}^{-1}$ are used in this study (see Trivers 1992).

In contouring the $5^{\circ}$ bin data, the "center of mass" of the locations of profiles used within the bin was taken as the $x, y$ location of the bin. We spline interpolated the $5^{\circ}$ square parameters to an evenly spaced $1^{\circ} \times 1^{\circ}$ grid and contoured the resulting evenly spaced grids for SNR, $r_{m}$, and $m_{l}$.

Finally, we investigated the sensitivity of the computed $m_{l}$ values to the choice of deep-pressure limit.

\section{Resulits}

Figures $4-7$ summarize the $5^{\circ}, 3000$-db results. Figure 4 lists the parameters $\mathrm{rms}\left(\Delta D^{\prime}\right)$ and $E_{\Delta D}$. Contour plots of the parameters designated in section 3 are shown in Figs. 5 and 6. Figure 7 gives first-baroclinicmode results. Additional parameters and other deeppressure limits are represented in figures given by Trivers (1992).

Section 4 a describes the 3000-db plots and compares the CAWO and historic plots for each parameter. Prior

TABLE 2. Hallock (1987) results.

\begin{tabular}{lcccc}
\hline \hline Location & $\begin{array}{c}\text { Pressure range } \\
(\mathrm{db})\end{array}$ & $\begin{array}{c}m \pm \sigma_{m_{l}} \\
(\mathrm{dyn} \mathrm{m} \mathrm{s})\end{array}$ & $\begin{array}{c}E_{\Delta D} \\
(\mathrm{dyn} \mathrm{m})\end{array}$ \\
\hline Southeastern Norwegian Sea & $20-1000$ & $-17.0 \pm 0.1$ & -0.998 & 0.0036 \\
Eastern Gulf Stream & $3-3000$ & $-31.3 \pm 0.7$ & -0.986 & 0.0670 \\
Western Sargasso Sea & $12-1950$ & $-38.9 \pm 1.6$ & -0.976 & 0.0129 \\
\hline
\end{tabular}




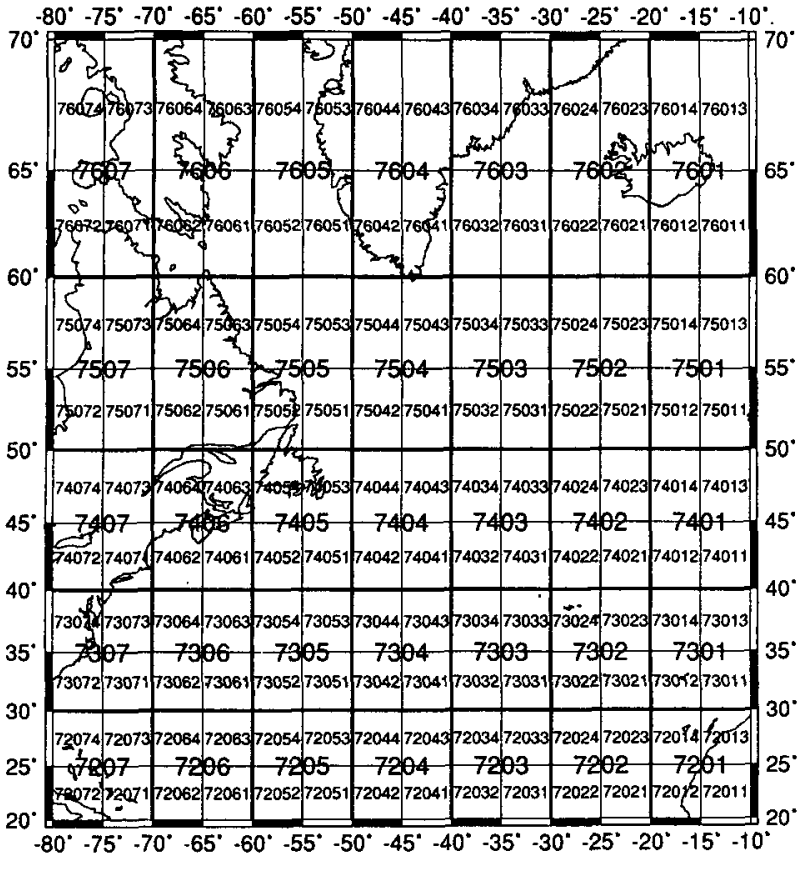

FIG. 3. WMO square numbering system.

to looking at the variation of $m_{l}$, one needs to establish the region in which $\Delta D$ is closely linearly related with $\tau$. This is accomplished by examining the correlation and error statistics, $r_{m}$ and SNR; $m_{l}$ is then examined in the region of strong correlation. Strong correlation is here taken to be $r_{m}<-0.9$, and in the contour plots of $m_{l}$ (Fig. 6), this region, for the corresponding correlation coefficient, is shown as an unshaded region: Section $4 \mathrm{~b}$ gives the results of $m_{l}$ calculations for different deep-pressure limits. Section $4 \mathrm{c}$ presents the results of $m_{1}$ calculations.

\section{a. Plots of 0-3000-db integrations}

\section{1) SNR}

The CAWO and historic SNR contour plots (Fig. 5) are similar. In particular, SNR is greater than $4 \mathrm{~dB}$ in a broad tongue encompassing the Gulf Stream, and this 4- $\mathrm{dB}$ contour has roughly the same shape and same position in both plots. In addition, the SNR $>4 \mathrm{~dB}$ region corresponds roughly to the $r_{m}<-0.9$ region for both the CAWO and historic data (Fig. 6).

\section{2) $\operatorname{rms}\left(\Delta D^{\prime}\right)$ AND $E_{\Delta D}$}

Figure 4 is a plot of $\operatorname{rms}\left(\Delta D^{\prime}\right)$ and $E_{\Delta D}$ for the CAWO and historic datasets. In both datasets, $\operatorname{rms}\left(\Delta D^{\prime}\right)$ is largest in the Gulf Stream, and the standard deviation of $\log _{10}\left[\mathrm{rms}\left(\Delta D^{\prime}\right)\right]$ is roughly twice the standard deviation of $\log _{10}\left(E_{\Delta D}\right)$. This demonstrates that variations in SNR are principally due to variations in signal, $\operatorname{rms}\left(\Delta D^{\prime}\right)$, rather than noise, $E_{\Delta D}$.
3) $r_{m}$

The CAWO and historic contour plots of $r_{m}$, represented as levels of shading in Fig. 6, are similar. Both show strong negative correlation $\left(r_{m}<-0.9\right)$ in a brcad tongue extending eastward from the American continent and curling toward the north. This region encompasses the Gulf Stream and the North Atlantic Current. South of about $30^{\circ} \mathrm{N}$ in both plots, the correlations deteriorate, becoming especially weak in the case of the CAWO $r_{m}$. Both plots also show correlation weakening significantly north of $45^{\circ} \mathrm{N}$ in the west.

\section{4) $m_{l}$}

Figures $6 \mathrm{a}$ and $6 \mathrm{~b}$ are also contour plots of $m_{l}$ derived from the CAWO and historic datasets. The two plots show broad similarities. The $m_{l}$ has largest magnitude $\left(m_{l}<-40\right.$ dyn $\left.\mathrm{m} \mathrm{s}^{-1}\right)$ in the northern Sargasso Sea. In the Gulf Stream region, $m_{l}$ is approximately -30 to -35 dyn m s${ }^{-1}$ west of $65^{\circ} \mathrm{W}$. In both the Gulf Stream region east of $65^{\circ} \mathrm{W}$ and the North Atlantic Current region, $m_{l}$ is approximately -25 to $-30 \mathrm{dyn} \mathrm{m} \mathrm{s}^{-1}$. Where the correlation is weaker (shaded area, $r_{m}$ $>-0.9$ ), the CAWO and historic plots disagree, confirming that the $m_{l}$ values are unreliable.

\section{b. Varying the pressure integration interval}

Table 3 shows the variation of $m_{l}$ with the deeppressure limit $p$ to which the integrations are carried. Results are given for two different $5^{\circ}$ squares in regions of strong correlation, one in the Gulf Stream (WMO

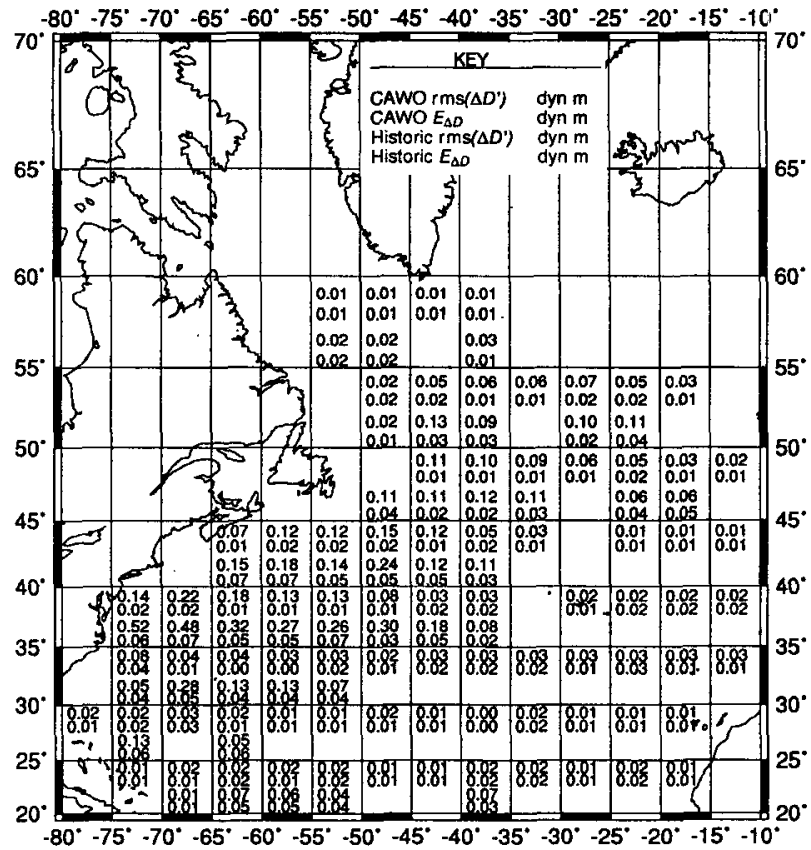

FIG. 4. The rms ( $\Delta D^{\prime}$ ) and $E_{\Delta D}$ for CAWO and historic datasets (see key); 0-3000-db, $5^{\circ}$ bins. 

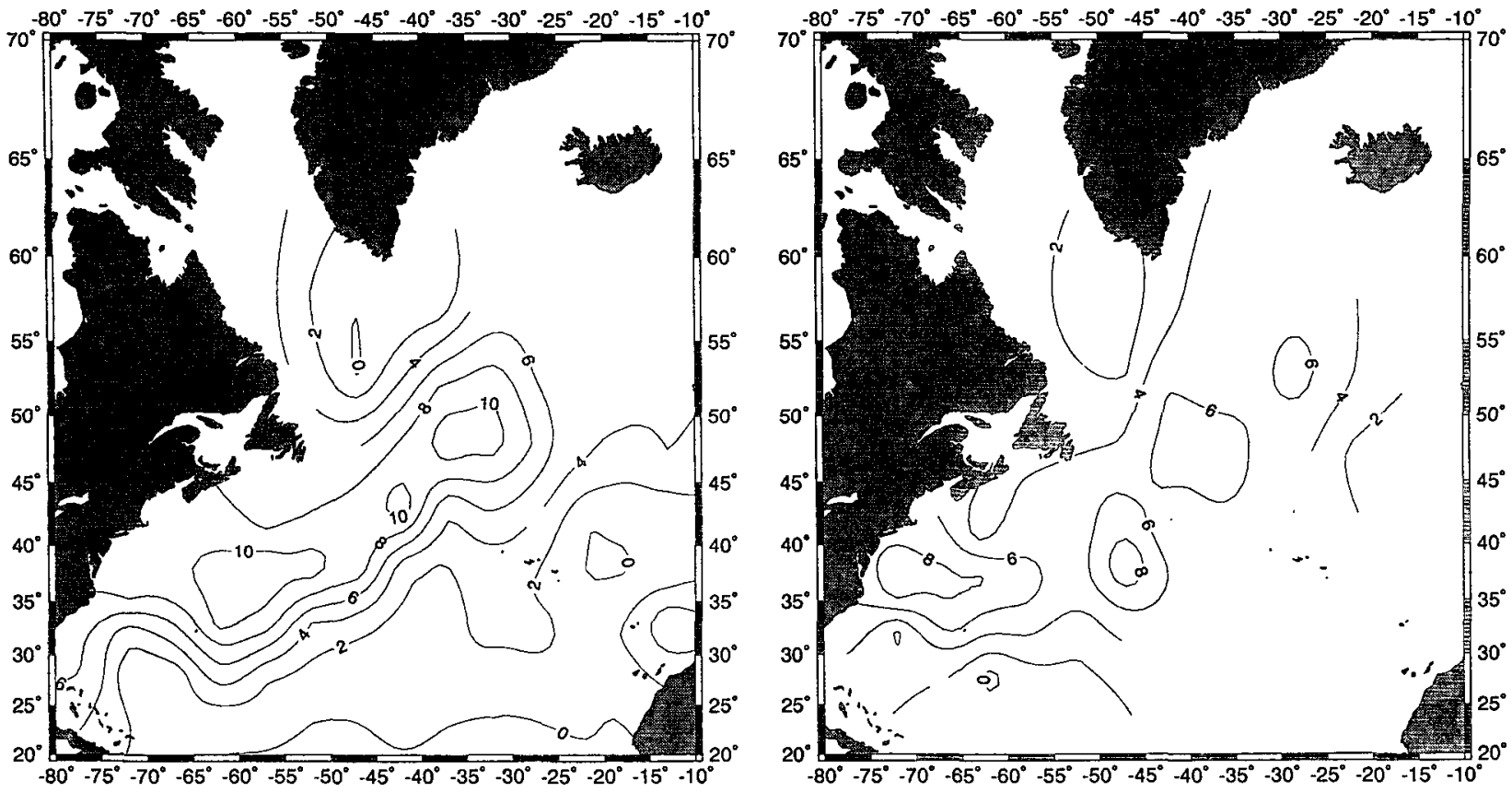

FIG. 5. Contour plot of SNR, 0-3000-db, $5^{\circ}$ bins, for (a) CAWO and (b) historic datasets. Contour interval $2 \mathrm{~dB}$.

number 73063) and the other in the North Atlantic Current (WMO number 74043). The magnitude of $m_{l}$ decreases slightly (less than $20 \%$, typically $3 \%$ ) as the pressure is reduced from 4000 to $1000 \mathrm{db}$.

Similarly Hallock (1987) found very little difference in Gulf Stream $m_{l}$ as the deep-pressure limit was changed from 3000 to $5000 \mathrm{db}$. Trivers (1992, appen$\operatorname{dix} \mathrm{H}$ ) shows the geographical variation of $m_{l}$ for other deep-pressure limits.

\section{c. First-baroclinic-mode $m_{1}$ and ratio $m_{l} / m_{1}$}

Figure 7 shows mean $m_{1}$ and $m_{l} / m_{1}$ values for the $5^{\circ}$ squares in the region, computed from the CAWO and historic datasets. The magnitude of $m_{1}$ is everywhere greater than 30 . It is smallest east of $45^{\circ} \mathrm{W}$ at about $45^{\circ} \mathrm{N}$, and grows in magnitude to the north, west, and south. The ratio $m_{l} / m_{1}$ has a largest value of 1.7 ; it has a value close to unity in the region of the Gulf Stream and North Atlantic Current.

\section{Discussion}

In this section, the following questions are addressed. Do the CAWO and historic $m$ 's compare favorably? Does $m_{l}$ computed here compare favorably with previous determinations? Why is the correlation of $\Delta D$ with $\tau$ weak in some regions? How does $m_{l}$ compare with $m_{1}$ ? What causes regional variations in $m$ ? Section $5 \mathrm{a}$ discusses the similarities between the CAWO and historic results. Section $5 \mathrm{~b}$ is a comparison with $m_{l}$ values from previous work. Section $5 \mathrm{c}$ discusses causes of weak correlation. Section 5d compares linearregression and first-baroclinic-mode results for $m$. Sec- tion $5 \mathrm{e}$ is an investigation of the variation of $m$ in regions of good correlation.

\section{a. Comparison of CAWO and historic $m_{l}$ 's}

Both the CAWO and historic correlations are strong in a region surrounding the Gulf Stream and its extension, the North Atlantic Current; in this region the $m_{l}$ values derived from the two datasets are similar (Fig. 6). Presumably, this is because temporal variations are predominantly due to the meanderings of the spatial structures associated with these major currents. Eddies may also contribute to variations in the historic data, but being derived from these currents are associated with similar $m_{l}$ values. Since their effects are largely averaged out in the CAWO dataset, these eddies probably account for the somewhat larger area of strong correlation for the historic dataset.

\section{b. Comparison of $m_{l}$ results to previous work}

Hallock (1987) obtained $m_{l}=-31.3 \pm 0.7$ dyn $\mathrm{m} \mathrm{s}^{-1}$ (Table 2) for Gulf Stream locations encompassed within the WMO $5^{\circ}$ squares 73054,73063 , and 73064. In these squares, for $m_{l} \pm \sigma_{m_{l}}$ the CAWO data give $-40.8 \pm 0.5,-38.0 \pm 0.6$, and $-35.0 \pm 0.8$ dyn $\mathrm{m} \mathrm{s}^{-1}$, respectively; the historic data give -34.2 $\pm 1.4,-32.9 \pm 0.6$, and $-34.2 \pm 0.7 \mathrm{dyn} \mathrm{m} \mathrm{s}{ }^{-1}$, respectively. All these $m_{l}$ values are significantly larger than Hallock's value, but the historic $m_{l}$ values are only slightly larger.

Hallock (1987) also obtained $m_{l}=-38.9 \pm 1.6$ dyn $\mathrm{m} \mathrm{s}^{-1}$ (Table 2) for a Sargasso Sea location in 

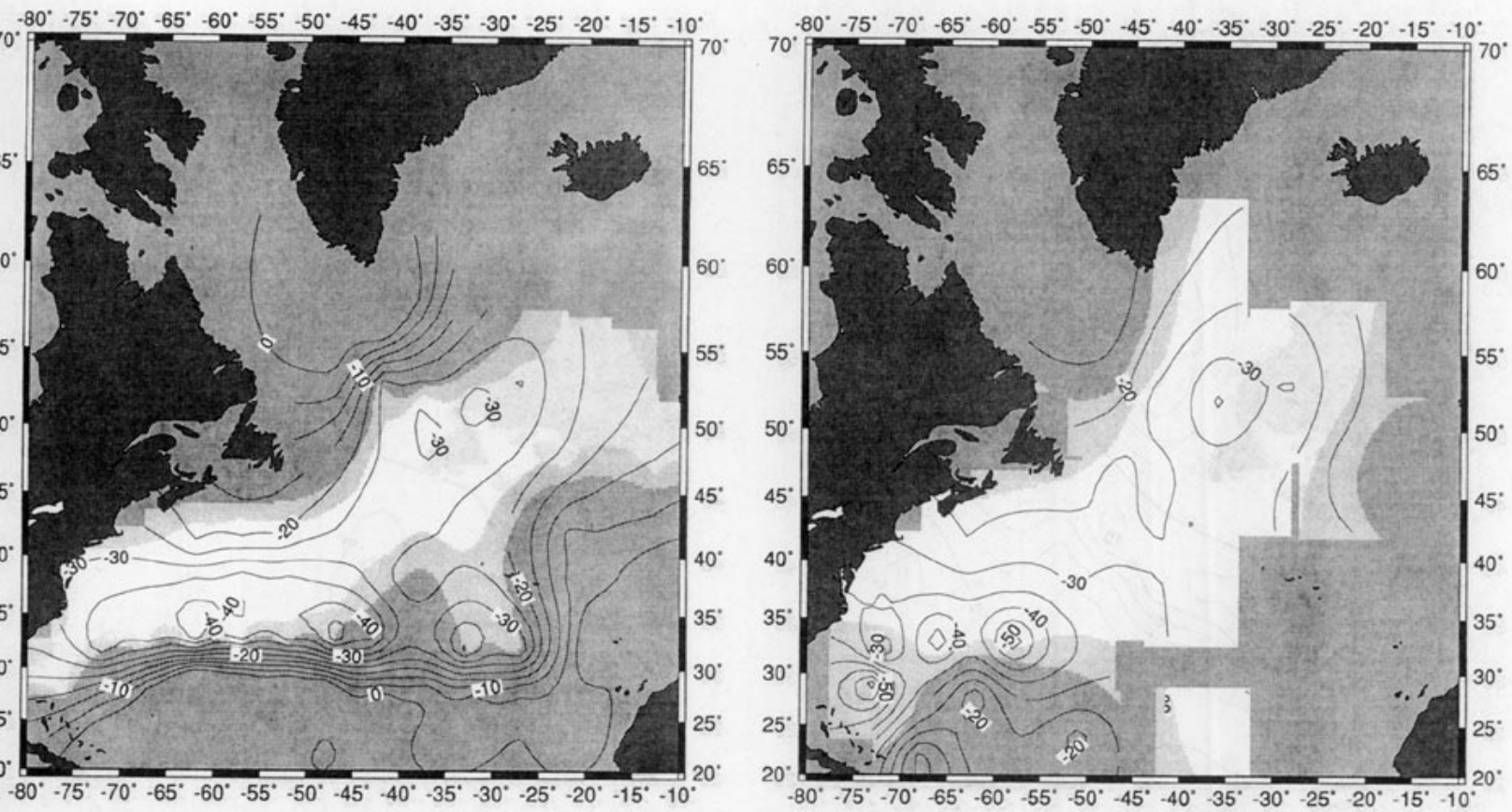

Fig. 6. Contour plot of $m_{l}, 0-3000-\mathrm{db}, 5^{\circ}$ bins, for (a) CAWO and (b) historic datasets. Contour interval is 5 dyn $\mathrm{m} \mathrm{s}^{-1}$. Corresponding correlations $r_{m}$ of $\Delta D$ with $\tau$ are shown by shading. Unshaded region has strong correlation $\left(r_{m}<-0.9\right)$. Lighter shaded region has fair correlation $\left(-0.9<r_{m}<-0.8\right)$. Darker shaded region has poor correlation $\left(-0.8<r_{m}\right)$ or is a region of no data (contours absent).

WMO square 73071 . In this square, the $0-2000-\mathrm{db}$ (closest to Hallock's pressure range) CAWO data give $m_{l}=-41.9 \pm 2.8$ dyn $\mathrm{m} \mathrm{s}^{-1}$ and the historic data give $m_{l}=-31.0 \pm 8.6 \mathrm{dyn} \mathrm{m} \mathrm{s}^{-1}$ (Trivers 1992). Taking into account their error ranges, both of these $m_{l}$ estimates are mutually consistent with Hallock's.

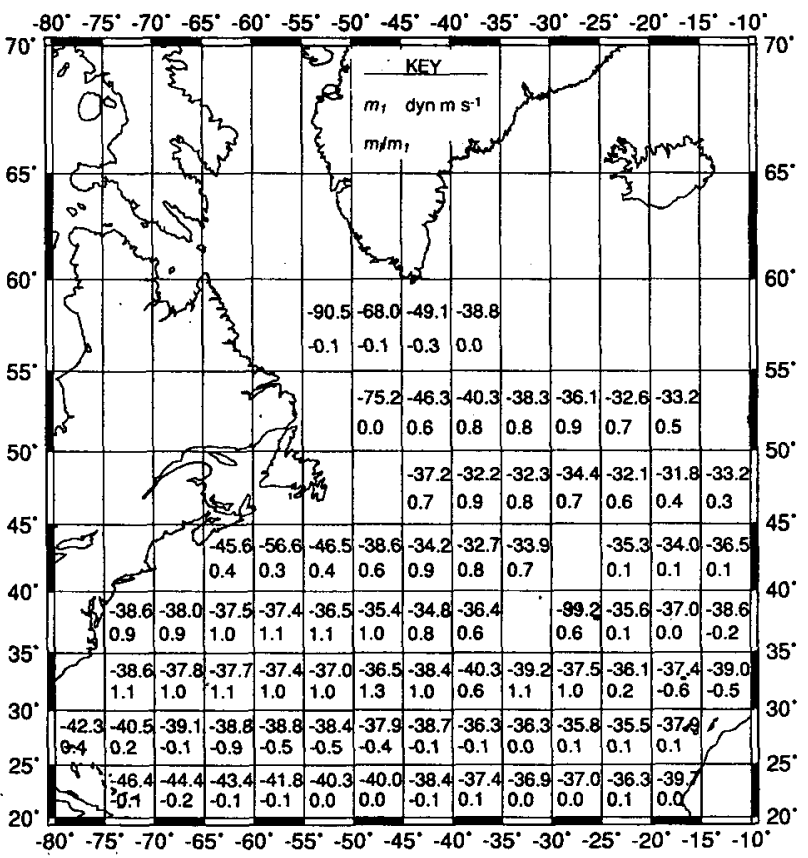

Watts and Rossby (1977) found good correlation of $\Delta D$ with $\tau$, and hence a value for $m_{l}$ (Table 1$)$, near $28^{\circ} \mathrm{N}, 70^{\circ} \mathrm{W}$ in the southwestern Sargasso Sea, an area of generally poor $\Delta D-\tau$ correlation in this study. Apparently, temporal variation at this site is not well represented by spatial variation within an encompassing

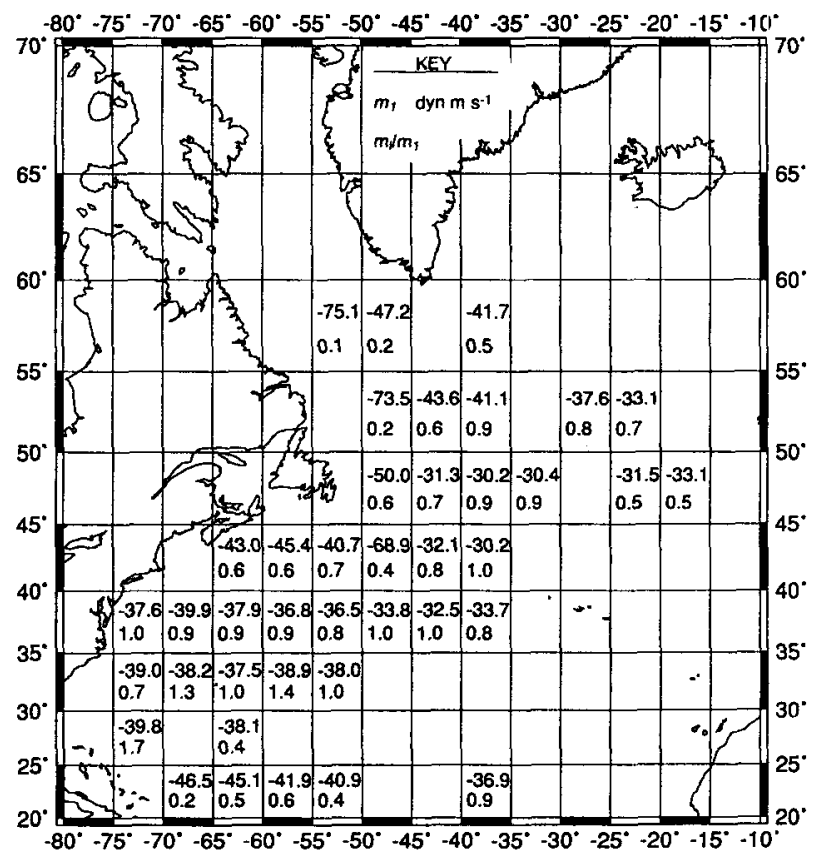

FIG. 7. Slope $m_{1}$ (upper number) and $m_{l} / m_{1}$ (lower number), 0-3000-db, $5^{\circ}$ bins, for (a) CAWO and (b) historic datasets. 
TABLE 3. Comparison of $m_{l}\left(\right.$ dyn $\left.\mathrm{m} \mathrm{s}^{-1}\right)$ for different pressure ranges (integrating from zero to "deep pressure").

\begin{tabular}{cccccc}
\hline \hline & \multicolumn{2}{c}{ Square 73063} & & \multicolumn{2}{c}{ Square 74043 } \\
\cline { 2 - 3 } \cline { 5 - 6 } $\begin{array}{c}\text { Deep pressure } \\
\text { (db) }\end{array}$ & CAWO & Historic & & CAWO & Historic \\
\hline 500 & -38.4 & -31.8 & & -22.4 & -14.7 \\
1000 & -37.8 & -32.3 & & -24.0 & -20.3 \\
2000 & -37.3 & -32.7 & & -24.7 & -20.4 \\
3000 & -38.0 & -32.9 & & -25.9 & -20.8 \\
4000 & -39.1 & -33.2 & & -28.8 & -21.1 \\
\hline
\end{tabular}

$500-\mathrm{km}$ region. Perhaps this is a consequence of small spatial variation associated with the relatively flat dynamic topography at the site, which is near the gyre center. In any case, Watts and Rossby's result indicates that an IES can sometimes be successfully used to determine $\Delta D$ even in regions of weak $r_{m}$ determined from geographically distributed data, that is, shaded regions of Fig. 6.

In the next section, the correspondence of spatial and temporal variabilities is considered in more detail.

\section{c. Causes of weak correlations}

An important reason for weak correlations in the south, east, and north is the small variance of the signals there (Fig. 4), resulting in the small $(<4 \mathrm{~dB})$ SNR (Fig. 5). The correlations are weak because the SNR is low.

Another possible explanation for the weak correlations $\left(r_{m}>-0.9\right)$ and small-magnitude $m_{i}$ 's south of $30^{\circ} \mathrm{N}$ and east of $25^{\circ} \mathrm{W}$ (Fig. 6) is the variable influence of high-salinity, high-temperature water originating in the Mediterranean Sea. To test this hypothesis, we computed the $m$ resulting from dynamic height change associated with the passage of a Mediterranean eddy (meddy). The $m_{l}$ value associated with the meddy has small magnitude, because sound speed $c$ is mainly controlled by water temperature and thus $\tau$ is significantly decreased by the warm meddy water. But the high salinity of that water largely compensates the temperature effect on density, so $\Delta D$ changes only slightly. Thus, there is a large difference between $m_{l}$ for the meddy signal and $m_{1}$ - whether computed inside or outside the meddy - for the first baroclinic mode (Table 4). The weak $r_{m}$ correlations in this region could arise from the combination of Mediterranean water and first-baroclinic-mode signals.

Anomalous $m_{l}$ values can also result from variable inputs of low-salinity water, and this was observed south of Newfoundland (Trivers 1992).

\section{d. Correspondence of $m_{l}$ with $m_{1}$}

Figure 7 shows values of $m_{1}$ and the ratio $m_{l} / m_{1}$ for the two datasets.

Values of $m_{l} / m_{1}$ between 0.8 and 1.2 are found in a region that generally corresponds to the region of
TABLE 4. Meddy-influenced $m$ determined by integrating from 0 to 1750 -db profiles taken inside and outside the meddy located near $36^{\circ} \mathrm{N}, 9^{\circ} 20 \mathrm{~W}, 17$ September 1988 . Here, $\delta$ represents the value inside the meddy minus the value outside. The $m_{1}$ and $\dot{m}_{1}$ represent, respectively, the first-baroclinic response of the background (i.e., outside the meddy) and of the meddy itself.

\begin{tabular}{ccccc}
\hline \hline $\begin{array}{c}\delta \tau \\
(\mathrm{s})\end{array}$ & $\begin{array}{c}\delta \Delta D \\
(\mathrm{dyn} \mathrm{m})\end{array}$ & $\begin{array}{c}m_{l} \\
\left(\text { dyn m s}^{-1}\right)\end{array}$ & $\begin{array}{c}m_{1} \\
\left(\mathrm{dyn} \mathrm{m} \mathrm{s}^{-1}\right)\end{array}$ & $\begin{array}{c}\dot{m}_{1} \\
\left(\text { dyn m s }^{-1}\right)\end{array}$ \\
\hline-0.0036 & 0.028 & -7.8 & -78 & -96 \\
\hline
\end{tabular}

strong $\Delta D-\tau$ correlation $\left(r_{m}<-0.9\right)$ in Fig. 6 . At first sight, $m_{l} / m_{1} \approx 1$ suggests variability in this region is predominantly due to first-baroclinic-mode motions. But the strong-correlation region is an area of strong currents (Gulf Stream and North Atlantic Current), and it is presumably meandering of these currents that is the principal source of variability. This meandering results in vertical movements of the thermocline, resembling those of first-baroclinic-mode disturbances; hence $m_{l}$ and $m_{1}$ are approximately equal in the region.

An exception to the general correspondence of the $m_{l} / m_{1} \approx 1$ and $r_{m}<-0.9$ regions is the slope water region north of the Gulf Stream, where correlation $r_{m}$ is strong but $m_{l} / m_{1} \approx 0.4$. Perhaps this is because thermocline depth variations relative to mean thermocline depth are assumed small in computing $m_{1}$, but are often not small in this region.

\section{e. Spatial variation of $m$}

The general trend of $m_{l}$, where it is well defined, is a decrease in magnitude to the north (Fig. 6). This is principally a result of the decrease in temperature of the water above the thermocline. Figure 8 shows $m$ as a function of temperature for a homogenous ocean layer $1000 \mathrm{~m}$ thick whose temperature is changed

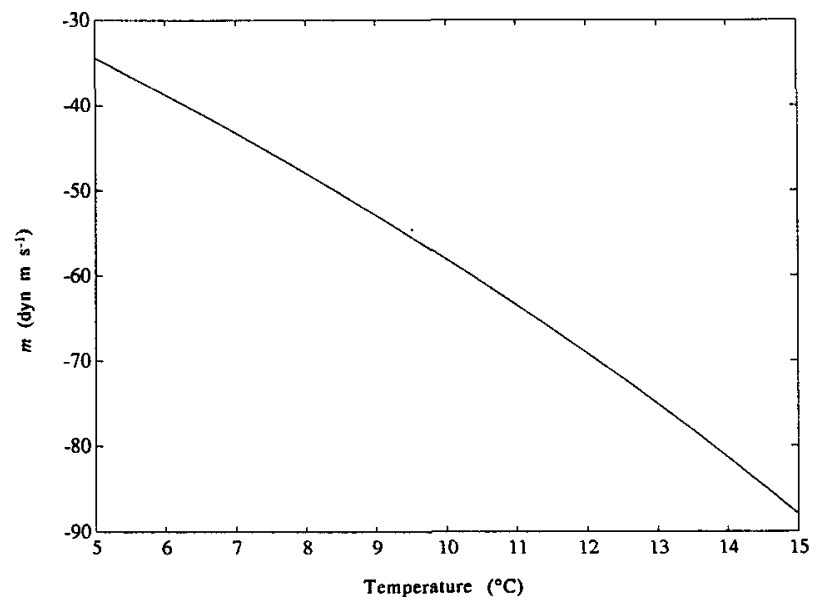

FIG. 8. Slope $m$ as a function of temperature, computed-from the equations of Millero et al. (1980) and Chen and Millero (1977) for $1000-\mathrm{m}$ water column of uniform salinity ( $35 \mathrm{psu}$ ) and uniform temperature, by imposing a $0.01{ }^{\circ} \mathrm{C}$ temperature change. 
slightly. It shows a steady decrease in magnitude of $m$ as the mean water-column temperature decreases. A typical depth-weighted average Sargasso Sea temperature for $0-1000 \mathrm{~m}$ is $12^{\circ} \mathrm{C}$, while a typical average North Atlantic Current temperature is $7^{\circ} \mathrm{C}$. Using this simple model, the associated $m$ values would be -70 and -45 dyn $\mathrm{m} \mathrm{s}^{-1}$, respectively. Going from the Sargasso Sea to the North Atlantic Current, this change in $m$ of 25 dyn m s$~^{-1}$ is slightly larger than the observed change of 20 dyn $\mathrm{m} \mathrm{s}^{-1}$.

The decrease in magnitude of $m$ with decreasing temperature is apparent from Fig. 10 in Watts and Rossby (1977). It is also apparent from their figure that $m$ depends on the $T-S$ diagram slope $A=d S / d T$, especially within the thermocline where the temperature gradient and the vertical displacement $\chi$ have extrema. Typically, in the North Atlantic Current $A$ $=0.05 \mathrm{psu}^{\circ} \mathrm{C}^{-1}$, and in the Sargasso Sea $A=0.14$ psu ${ }^{\circ} \mathrm{C}^{-1}$, within the permanent thermocline (Emery and Dewar 1982). From Watts and Rossby's (1977) Fig. 10, it appears that this change in $A$ significantly reduces the spatial variation of $m$ that one would expect from temperature alone. But the size of this reduction cannot be readily calculated, principally because of uncertainty about the actual form of $\chi$.

\section{Summary and conclusions}

A well-defined, linear relation between $\Delta D$ and $\tau$ is found in a single region of the North Atlantic. This region, centered on the Gulf Stream, is a broad tongue extending from the western Sargasso Sea almost to Ireland. Areas of weak correlations have variable salinity signals and resulting $T-S$ scatter. The value of $m_{l}$ typically ranges from -40 dyn $\mathrm{m} \mathrm{s}^{-1}$ in the northern Sargasso Sea to -20 dyn m s$^{-1}$ in the North Atlantic Current. In the Gulf Stream, it is typically between -30 and -35 dyn $\mathrm{m} \mathrm{s}^{-1}$. This variation is attributed principally to the temperature variation of surface-layer water (i.e., water above the thermocline). Where $m_{l}$ is well defined, its value usually corresponds roughly with that for small-amplitude first-baroclinic-mode excitement.

Accordingly, in this region, since correlation between $\Delta D$ and $\tau$ is strong, variations in acoustic travel time from an IES record can be reasonably interpreted as variations in dynamic height, if an appropriate conversion factor $m$ is used.

Acknowledgments. Dr. D. R. Watts and Mr. S. D. Howden kindly gave much helpful advice. Dr. M. McCartney and Dr. H. T. Rossby supplied the historic and CAWO data, respectively. The meddy data were supplied by Dr. M. Prater. This work was supported by the National Science Foundation (NSF) and the Office of Naval Research through NSF Grant OCE9018581. One author (GT) thanks the U.S. Coast Guard for the support of his graduate studies, during which this work was carried out. The other (MV) thanks the New Zealand Oceanographic Institute for sabbatical support provided during the final editing of this paper.

\section{REFERENCES}

Chen, C.-T., and F. J. Millero, 1977: Speed of sound in seawater at high pressures. J. Acoust. Soc. Amer., 62, 1129-1135.

Chiswell, S. M., D. R. Watts, and M. Wimbush, 1986: Using inverted echo sounders to measure dynamic height in the eastern equatorial Pacific during the 1982-83 El Niño. Deep-Sea Res., 33, 981-991.

,-- , and -1987 : Inverted echo sounder observations of variability in the eastern equatorial Pacific during the 1982-83 El Niño. Deep-Sea Res., 34, 313-327.

- M. Wimbush, and R. Lukas, 1988: Comparison of dynarnic height measurements from an inverted echo sounder and an island tide gauge in the central Pacific. J. Geophys. Res., 93, 2277-2283.

Emery, W. J., and J. S. Dewar, 1982: Mean temperature-salinity, salinity-depth and temperature-depth curves for the North Atlantic and the North Pacific. Progress in Oceanography, Vol. 11, Pergamon Press, 219-305.

Fofonoff, N. P., and R. C. Millard, 1983: Algorithims for computation of fundamental properties of seawater. UNESCO Tech. Papers in Marine Science, 44, $53 \mathrm{pp}$.

Hallock, Z. R., 1987: Regional characteristics for interpreting inverted echo sounder (IES) observations. J. Atmos. Oceanic Technol., 4, 298-304.

Katz, E. J., 1987: Seasonal response of the sea surface to the wind in the equatorial Atlantic. J. Geophys. Res., 92, 1885-1893.

Levitus, S., 1982: Climatological Atlas of the World Ocean. NOAA Professional Paper 13, Rockville, MD, 173 pp.

Maul, G. A., J. R. Proni, M. Bushnell, and J. L. Mitchell, 19:38: Oceanic dynamic height anomaly from Geosat: A conceptual model for short collinear orbit segments. Mar. Geodesy, 12 , 313-327.

Miller, L. L., D. R. Watts, and M. Wimbush, 1985: Oscillations of dynamic topography in the eastern equatorial Pacific. J. Phys. Oceanogr., 15, 1759-1770.

Millero, F. J., C.-T. Chen, A. Bradshaw, and K. Schleicher, 1980: A new high pressure equation of state for seawater. Deep-Sea Res., 27, 255-264.

Rossby, H. T., 1969: On monitoring depth variations of the main thermocline acoustically. J. Geophys. Res., 74, 5542-5546.

Trivers, G. A., 1992: Regional characteristics of acoustic travel time interpretations in the North Atlantic. M.S. thesis, Graduate School of Oceanography, University of Rhode Island, $154 \mathrm{pp}$.

Watts, D. R., and H. T. Rossby, 1977: Measuring dynamic heights with inverted echo sounders: Results from MODE. J. Phys. Oceanogr., 7, 345-358.

Wimbush, M., S. M. Chiswell, R. Lukas, and K. A. Donohue, 1990: Inverted echo sounder measurement of dynamic height through an ENSO cycle in the central equatorial Pacific. IEEE J. Oce'an Eng., 15, 380-383. 